\title{
Modeling the influence of external factors on students' memorization performance in general chemistry
}

\author{
Vladimir Shelontsev, and Irina Gerasimova \\ Omsk State Pedagogical University, Omsk, Russia
}

\begin{abstract}
The article provides theoretical and empirical justification for the use of multivariate methods of analysis to implement different types of models in the study of the productivity of involuntary and combined memorization by students in learning chemistry.
\end{abstract}

\section{Introduction}

Statistical methods of analysis allow us to solve experimental problems in chemistry teaching methodology, the result of which is the construction of models of pedagogical phenomena. Depending on what means, under what conditions, and in relation to what objects of cognition the ability of models to reflect reality is carried out, there is a great variety of models, as well as typologies [1]. For the study of psychological and pedagogical phenomena and educational process, the typology based on the most important functions of a scientific theory, namely: description, explanation, prediction is the most suitable. According to the functional feature, there are descriptive models, interpretive or explanatory models, and predictive models [2].

Description model can be called any description of an object or any phenomenon, including in psychological and pedagogical researches. These models simply state characteristics and properties of an object, but they do not explain why these phenomena have such and not another nature.

Another class of models is used to determine the causes, factors of functioning of an object or phenomenon. These are the so-called explanatory models. They perform an interpretive function; their creation makes it possible to answer the question of why something happens in such a way.

The last type of models is predictive. They are necessary for distribution of research results on similar or close to similar situations, and for possibility to describe object behavior in these situations, possibility to foresee its development in the future. Thus, this type of models answers the question of what changes this or that impact on the object under study will lead to. Predictive models are not required to include explanatory models. It is often possible to obtain a satisfactory prediction based on empirical generalizations, that is, using only descriptive model data.

The implementation of the predictive function most often occurs using the multivariate analysis methods, such as variance and regression analysis. Models obtained with the help 
of these methods allow making a qualitative (variance) or quantitative (regression) analysis of the applied pedagogical impact, based on which it is necessary to make a prediction.

Memory takes one of the important places in the system of cognitive activity and, as a cognitive process, it includes memorization, storage and reproduction of information. The process of memorization is determinant in the system of memory processes. P.I. Zinchenko [3], A.A. Smirnov [4], G.K. Sereda [5] point out that thinking is a necessary condition for memorization, as fixing material in the memory is accompanied by its logical processing, which relies on revealing connections and relations in this material.

\section{Materials and methods}

The aim of the ongoing experimental study is to build explanatory and predictive models of the influence of external factors on students' involuntary and combined memorization performance in general chemistry.

The experimental study was carried out on the basis of the Federal State Budgetary Educational Institution of Higher Education (FSBEI) Omsk State Pedagogical University. This experiment involved 1st-year students in Pedagogical education specification; "Biology and chemistry"; "Chemistry and life safety".

During the experiment, the influence of the following factors on the students' semantic memorization performance of learning chemical material was studied:

1) Type of memorization;

2) Amount of learning material;

3) Time of work with the learning material.

The dependent variable was the memorization performance coefficient (Cmp), which is calculated according to the formula (1):

$$
C_{m p}=\frac{\mathrm{n}}{\mathrm{N}}
$$

where $\mathrm{n}$ is the number of memorized units of learning information, and $\mathrm{N}$ is the initial total number of units of learning information.

We studied the effect of two types of memorization: involuntary and combined. They differ in their aim. In involuntary memorization, the aim is to carry out a cognitive activity, to solve some cognitive problem, for example, to classify chemical objects, to exclude "excessive" chemical object from the set, etc. When implementing combined memorization, a mnemic aim is set. That is, to memorize the proposed material. However, at the same time a cognitive technique is given, which contributes to the most effective achievement of the mnemic aim $[3,4]$.

The experimental study was based on the methods of P.I. Zinchenko [3] and A.N. Shlychkova $[6,7]$ adjusted to the chemical content. Twenty cards with the formulas of the main classes of inorganic compounds ( 5 formulas of each class) were used as experimental material:

A) Oxides: $\mathrm{NO}, \mathrm{CaO}, \mathrm{MgO}, \mathrm{CO}_{2}, \mathrm{P}_{2} \mathrm{O}_{5}$.

B) Bases: $\mathrm{NaOH}, \mathrm{Ba}(\mathrm{OH})_{2}, \mathrm{KOH}, \mathrm{Ca}(\mathrm{OH})_{2}, \mathrm{Mg}(\mathrm{OH})_{2}$.

C) Acids: $\mathrm{H}_{2} \mathrm{SO}_{4}, \mathrm{HNO}_{3}, \mathrm{HCl}, \mathrm{H}_{2} \mathrm{CO}_{3}, \mathrm{H}_{3} \mathrm{PO}_{4}$.

D) Salts: $\mathrm{CaCO}_{3}, \mathrm{NaCl}, \mathrm{Na}_{2} \mathrm{SO}_{4}, \mathrm{KNO}_{3}, \mathrm{AlPO}_{4}$.

In order to study the effect of the amount of learning material from these cards, sets with different numbers of chemical formulas - from 8 to 20 - were compiled.

The effect of cognitive activity time was assessed in three variants: 3,5 , and 10 minutes.

The essence of the method is that the students were given sets of cards, with which they worked for different time, solving a cognitive problem of classification of inorganic substances or mnemic problem using the cognitive method of classification (depending on the experimental series). 
Statistical processing and experimental data analysis were used to build models, using SSPS statistical software package. Recommendations outlined in the article [8] were used to build the models.

In the present study, 18 experimental series (ES) were conducted, which are shown in Table 1. Ten students participated in each experimental series.

Table 1. Experimental series

\begin{tabular}{|c|c|c|c|c|c|c|}
\hline $\begin{array}{c}\text { Time, min. } \\
\begin{array}{c}\text { Number of chenical } \\
\text { formulas }\end{array}\end{array}$ & $\mathbf{8}$ & $\mathbf{1 5}$ & $\mathbf{2 0}$ & $\mathbf{8}$ & $\mathbf{1 5}$ & $\mathbf{2 0}$ \\
\cline { 2 - 7 } & Involuntary memorization & \multicolumn{3}{|c|}{ Combined memorization } \\
\hline 3 min. & $\mathrm{ES}_{1}$ & $\mathrm{ES}_{2}$ & $\mathrm{ES}_{3}$ & $\mathrm{ES}_{10}$ & $\mathrm{ES}_{11}$ & $\mathrm{ES}_{12}$ \\
\hline 5 min. & $\mathrm{ES}_{4}$ & $\mathrm{ES}_{5}$ & $\mathrm{ES}_{6}$ & $\mathrm{ES}_{13}$ & $\mathrm{ES}_{14}$ & $\mathrm{ES}_{15}$ \\
\hline 10 min. & $\mathrm{ES}_{7}$ & $\mathrm{ES}_{8}$ & $\mathrm{ES}_{9}$ & $\mathrm{ES}_{16}$ & $\mathrm{ES}_{17}$ & $\mathrm{ES}_{18}$ \\
\hline
\end{tabular}

\section{Results and discussion}

All data obtained in the experimental series are shown in Table 2. Models showing explanatory functions should be based on the simultaneous use of several statistical methods or multivariate methods of analysis [9]. Based on the experimental data obtained, it is possible to build the specified models.

Table 2. Number of chemical formulas (cf) memorized by students in the case of involuntary (numerator) and combined (denominator) memorization at different gradations of factors during the solution of the classification problem

\begin{tabular}{|c|c|c|c|c|c|c|c|c|c|}
\hline \multirow[b]{2}{*}{$\begin{array}{c}\text { Studen } \\
\text { t ID }\end{array}$} & \multicolumn{9}{|c|}{ Conditions for memorization of learning chemical material } \\
\hline & $\begin{array}{c}8 \mathrm{cf} \\
3 \mathrm{~min} . \\
\mathbf{E S}_{1} / \mathbf{E S}_{1} \\
0\end{array}$ & $\begin{array}{c}15 \mathrm{cf} \\
3 \mathrm{~min} . \\
\mathbf{E S}_{2} / \mathbf{E S}_{1} \\
\quad 1\end{array}$ & $\begin{array}{c}20 \mathrm{cf} \\
3 \mathrm{~min} . \\
\mathrm{ES}_{3} / \mathbf{E S}_{1} \\
2\end{array}$ & $\begin{array}{c}8 \mathrm{cf} \\
5 \mathrm{~min} . \\
\mathrm{ES}_{4} / \mathrm{ES}_{1} \\
3\end{array}$ & $\begin{array}{c}15 \mathrm{cf} \\
5 \mathrm{~min} . \\
\mathrm{ES}_{5} / \mathrm{ES}_{1} \\
\quad 4\end{array}$ & $\begin{array}{c}20 \mathrm{cf} \\
5 \mathrm{~min} . \\
\mathrm{ES}_{6} / \mathrm{ES}_{1} \\
5\end{array}$ & $\begin{array}{c}8 \mathrm{cf} \\
10 \mathrm{~min} . \\
\mathrm{ES}_{7} / \mathrm{ES}_{1} \\
6\end{array}$ & $\begin{array}{c}15 \mathrm{cf} \\
10 \mathrm{~min} . \\
\mathrm{ES}_{\mathbf{8}} / \mathrm{ES}_{\mathbf{1}} \\
7 \\
7\end{array}$ & $\begin{array}{c}20 \mathrm{cf} \\
10 \mathrm{~min} . \\
\mathrm{ES}_{9} / \mathrm{ES}_{1} \\
8\end{array}$ \\
\hline 1 & $7 / 8$ & $9 / 12$ & $9 / 11$ & $8 / 8$ & $10 / 12$ & $10 / 12$ & $8 / 8$ & $10 / 12$ & $10 / 12$ \\
\hline 2 & $7 / 7$ & $8 / 11$ & $8 / 11$ & $7 / 8$ & $9 / 11$ & $9 / 11$ & $8 / 8$ & $9 / 12$ & $10 / 11$ \\
\hline 3 & $6 / 7$ & $8 / 11$ & $7 / 10$ & $7 / 7$ & $8 / 11$ & $9 / 11$ & $7 / 8$ & $9 / 11$ & $9 / 11$ \\
\hline 4 & $6 / 7$ & $7 / 10$ & $7 / 10$ & $7 / 7$ & $8 / 11$ & $8 / 10$ & $7 / 8$ & $8 / 11$ & $8 / 11$ \\
\hline 5 & $6 / 6$ & $7 / 9$ & $7 / 10$ & $6 / 7$ & $8 / 10$ & $8 / 10$ & $7 / 7$ & $8 / 10$ & $7 / 10$ \\
\hline 6 & $6 / 6$ & $7 / 9$ & $7 / 9$ & $6 / 7$ & $7 / 10$ & $8 / 10$ & $6 / 7$ & $8 / 10$ & $7 / 10$ \\
\hline 7 & $6 / 6$ & $6 / 9$ & $6 / 8$ & $6 / 6$ & $7 / 9$ & $7 / 10$ & $6 / 7$ & $7 / 10$ & $7 / 10$ \\
\hline 8 & $5 / 6$ & $6 / 8$ & $6 / 8$ & $6 / 6$ & $7 / 9$ & $7 / 9$ & $6 / 7$ & $7 / 9$ & $6 / 9$ \\
\hline 9 & $5 / 5$ & $6 / 8$ & $6 / 7$ & $5 / 6$ & $6 / 9$ & $6 / 9$ & $6 / 6$ & $6 / 9$ & $6 / 9$ \\
\hline 10 & $5 / 5$ & $6 / 7$ & $5 / 7$ & $5 / 6$ & $6 / 8$ & $6 / 9$ & $6 / 6$ & $6 / 8$ & $5 / 8$ \\
\hline
\end{tabular}

A certain type of explanatory model can be a model that takes into account the influence of several factors simultaneously, as well as their mutual influence. It is known that many factors of pedagogical influence are in close interrelation and can either strengthen each other's action or weaken it. Thus, building a model that would simultaneously take into account the action of several factors is of great interest. For this purpose, a factor model using multiple analysis of variance was applied.

This explanatory model studied the influence of three factors on the memorization of learning chemical material when 1st-year students were solving a cognitive problem of classification of chemical objects. Let us introduce the designation of the factors.

Factor A - amount of memorized chemical formulas: minimum - 8 formulas, average 15 , maximum - 20 formulas; factor $\mathrm{B}$ - memorization time: minimum -3 minutes, average 5 , maximum - 10 minutes; factor $\mathrm{C}$ - type of memorization: involuntary, combined. 
To build this model, the experimental data shown in Table 2 were used as input. To process the experimental data, the method of multiple analysis of variance was applied, namely $3 \times 3 \times 2$. The values of factors $\mathrm{A}, \mathrm{B}$ are given in the interval scale, and factor $\mathrm{C}$ is shown in the nominative scale in two gradations.

The full model of the influence of the three factors can be represented as follows (2):

$$
\mathrm{Y}=\mathrm{A}+\mathrm{B}+\mathrm{C}+\mathrm{AB}+\mathrm{BC}+\mathrm{AC}+\mathrm{ABC}
$$

The results of the calculation performed at the level of significance with $p=0.01$ show that all three studied factors separately influence the memorization performance coefficient, and there is a significant combined influence of two factors: the amount of learning material and the type of memorization. This model provides a comprehensive description of the studied factors, but it also has an explanatory function. It shows that when organizing the chemistry learning process aimed at increasing the performance of meaningful memorization, it is necessary to optimally combine the amount of learning material, type of memorization, and time of work with the learning material in the process of cognitive activity.

In particular, the resulting model shows that the most productive is the memorization in the combined form, which is carried out with a number of chemical objects not exceeding 20. Thus, the empirical model of the significant influence of factors is presented as follows (3):

$$
\mathrm{MP}=\mathrm{F}_{\mathrm{A}}+\mathrm{F}_{\mathrm{B}}+\mathrm{F}_{\mathrm{C}}+\mathrm{F}_{\mathrm{A}} \mathrm{F}_{\mathrm{C}}
$$

Predictive is a higher level of cognitive models [10]. They integrate the functions of description and explanation. An example of a predictive model is the model obtained by the method of multiple regression analysis. The basic regression equation has the following form (4):

$$
\mathrm{y}=a_{0}+a_{1} x_{1}+a_{2} x_{2}+a_{3} x_{3}+a_{1,2} x_{1} x_{2}+a_{2,3} x_{2} x_{3}+a_{1,3} x_{1} x_{3}+a_{1,2,3} x_{1} x_{2} x_{3},
$$

The processing of empirical data resulted in regression equations for involuntary and combined memorization (5), (6):

$$
\begin{gathered}
\mathrm{Y}(\mathrm{im})=a_{0}+b_{1} x_{1}+b_{2} x_{2}, \\
\mathrm{y}(\mathrm{cm})=a_{0} *+b_{1} * x_{1} *+b_{2} * x_{2} *
\end{gathered}
$$

After substituting the coded variables, we obtain regression models in explicit form (7), (8):

$$
\begin{aligned}
& \mathrm{C}_{\mathrm{mp}(\mathrm{im})}=5,145+0,094 \mathrm{n}+0,092 \mathrm{t}, \\
& \mathrm{C}_{\mathrm{mp}(\mathrm{cm})}=4,370+0,262 \mathrm{n}+0,112 \mathrm{t},
\end{aligned}
$$

where $\mathrm{C}_{\mathrm{mp}(\mathrm{im})}$ and $\mathrm{C}_{\mathrm{mp}(\mathrm{cm})}$ are the memorization performance coefficients of learning chemical material in the involuntary and combined form, respectively; $n$ is the index of the number of chemical objects (chemical formulas); $t$ is the time of work with the learning material.

The obtained equations show that the regression coefficients $\left(b_{1} *\right.$ and $\left.b_{2}{ }^{*}\right)$ are higher for combined memorization than for involuntary memorization. This indicates a greater influence on the amount of learning material and time per $\mathrm{C}_{\mathrm{mp}}$ value. These models can be visualized in the form of three-dimensional diagrams, as shown in Figures 1 and 2. 


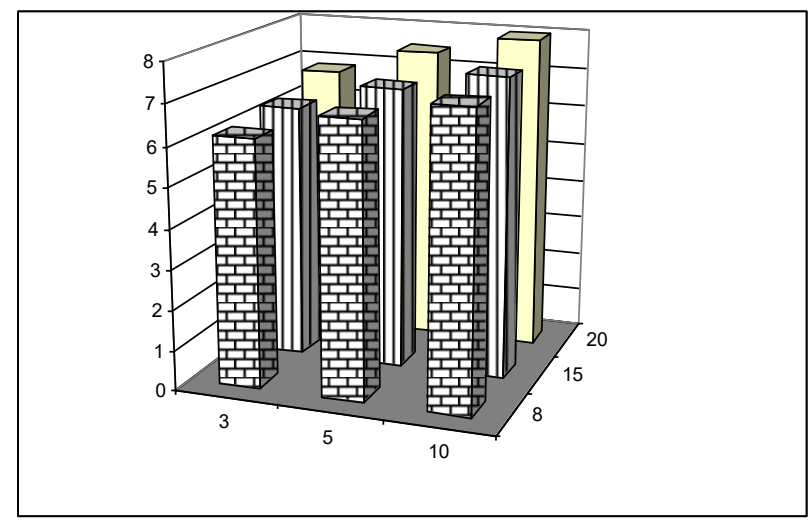

Fig. 1. Regression model for involuntary memorization

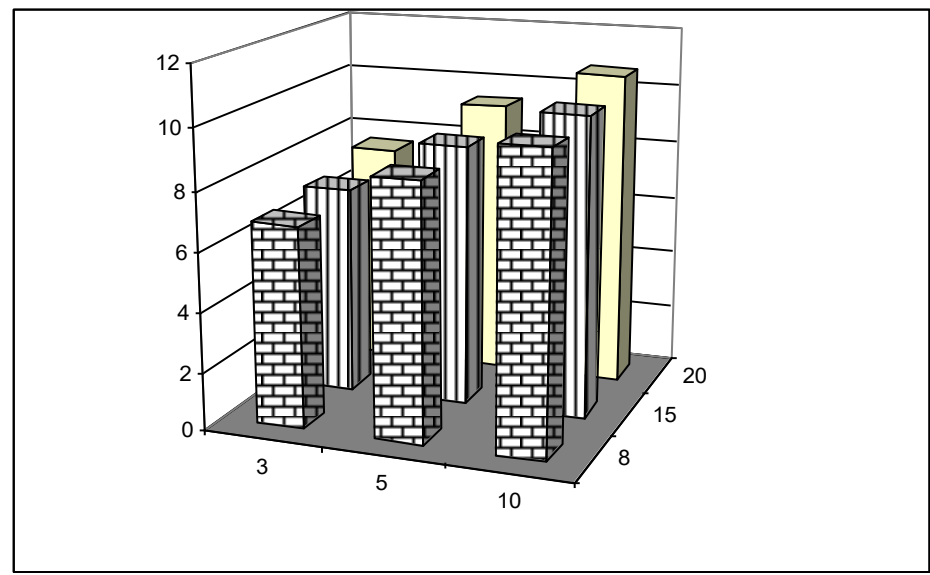

Fig. 2. Regression model for combined memorization

The predictive function of these models is manifested in the fact that knowing the number of units of learning information with which the student carries out cognitive activity, and the time of work with them, it is possible to calculate $\mathrm{C}_{\mathrm{mp}}$ more precisely, which is determined by the number of memorized units of learning material.

\section{Conclusions}

Based on the study, the following main conclusions can be formulated:

1. Important methods of modeling complex pedagogical processes include multivariate methods of analysis, which allow obtaining models that implement descriptive, explanatory, and predictive functions of scientific theory.

2. The influence of different factors on the students' memorization performance of learning chemical material was studied: amount of learning material, time of work with it and type of memorization by method of multiple analysis of variance. It was found that the combined memorization of learning chemical material is more productive, the factor empirical model of which has the following form:

$$
\mathrm{MP}=\mathrm{F}_{\mathrm{A}}+\mathrm{F}_{\mathrm{B}}+\mathrm{F}_{\mathrm{C}}+\mathrm{F}_{\mathrm{A}} \mathrm{F}_{\mathrm{C}}
$$


3. The method of multiple regression analysis was used to obtain a predictive model of the influence of the studied factors. The calculated regression models for involuntary and combined memorization have the following form:

$$
\begin{aligned}
& \mathrm{Cmp}(\mathrm{im})=5,145+0,094 \mathrm{n}+0,092 \mathrm{t} \\
& \mathrm{Cmp}(\mathrm{cm})=4,370+0,262 \mathrm{n}+0,112 \mathrm{t}
\end{aligned}
$$

These models indicate that they can be used to predict the level of students' memorization performance of learning chemical material, provided that the number of units of information and the duration of cognitive or mnemic activity of students with this information is known in advance.

\section{References}

1. B.Y. Sovetov, S.A. Yakovlev, Modeling systems, 271 (1985)

2. V.A. Shelontsev, A.V. Kuzin, L.N. Shelontseva, Models and methods of modeling in social and pedagogical researches, 183 (2010)

3. P.I. Zinchenko, Involuntary memorization, 717 (2010)

4. A.A. Smirnov, Problems of memory psychology, 423 (1996)

5. G.K. Sereda, PsyAnima, Dubna Psychological Journal (2009) http://www.psyanima.su/

6. A.N. Shlychkova, Psychological issues, 6, 81 (1982)

7. A.N. Shlychkova, Psychological issues, 6, 90 (1980)

8. Achim Buehl, Peter Zöfel, SPSS: the art of information processing. Analysis of statistical data and reconstruction of hidden regularities, 608 (2005)

9. A.D. Nasledov, Mathematical methods of psychological research, Data analysis and interpretation, 392 (2006)

10. E.M. Chetyrkin, Statistical methods of prediction, 200 (1977) 